\title{
Pseudo AV block produced by concealed extrasystoles arising below the bifurcation of the His bundle
}

\author{
Agustin Castellanos, Benjamin Befeler, and Robert J. Myerburg \\ From the Medical Service, Veterans Administration Hospital, and the Division of Cardiology, Department of \\ Medicine, University of Miami School of Medicine, Miami, Florida, U.S.A.
}

In the majority of the reported cases where concealed extrasystoles caused pseudo $A V$ block, impulse formation occurred above the so-called bifurcation of the His bundle. The two patients reported in this communication, however, showed manifest and concealed ectopic impulses originating in the left bundle-branch or its posteroinferior division. Both had prolonged HV intervals which were attributed to organic disease of the distal ventricular specialized conducting system. The ectopic beats remained confined to the two major compartments of the $A V$ conducting system, namely $A V$ nodal and ventricular specialized. Thus, for the purposes of concealment the $A V$ junction extended from the atrial pre- $A V$ nodal regions to the peripheral (physiological) ventricular 'gates'.

In 1947, Langendorf and Mehlman first postulated that premature beats confined to the 'AV node' (that is, without activating either atria or ventricles) could simulate first and (or) second-degree AV block. Thereafter other authors, using a similar deductive process, have reported probable examples of concealed 'AV nodal' or 'AV junctional' extrasystoles (Langendorf, 1958; Need and Fisch, 1962; Langendorf and Pick, 1966; Schamroth and Surawicz, 1971 ; Lindsay and Schamroth, 1973).

However, it was not until the advent of the catheter technique for recording the electrical activity of the ventricular specialized conducting system that the validity of these assumptions was corroborated. In 1970, Rosen, Rahimtoola, and Gunnar recorded His bundle and right bundle-branch electrograms in a patient with abrupt unexplained periods of second-degree AV block (either type I or type II).

- Intracardiac studies showed that the latter resulted from the occurence of premature His bundle depolarizations which produced the unusual effects on AV conduction because they were confined to the AV junction. These premature depolarizations appeared to originate above the so-called bifurcation of the His bundle. Rosen et al. coined the term ' 'pseudo AV block' because the underlying arrhythmia was most probably caused by a disturbance

Received 16 October 1973. in automaticity rather than to one in conductivity. Other authors have also recorded His bundle electrograms in patients with concealed His bundle extrasystoles (Cannon et al., 1972; Eugster et al., 1973; Narula, 1973). These reports led us to re-evaluate the tracings of two patients discussed in a previous communication (Castellanos et al., 1972) in whom pseudo AV block appeared to have been produced by extrasystoles arising below the bifurcation of the His bundle.

In both patients intracardiac recordings were performed after explaining the procedure to the patients and relatives and obtaining written consent (Castellanos et al., 1972).

\section{Case reports}

\section{Case I}

This 66-year-old man had a previous history of myocardial infarction and paroxysmal arrhythmias (Case 4 of the article by Castellanos et al., 1972).

Sinus beats showed complete right bundle-branch block associated with left anterior hemiblock. The corresponding AV conduction intervals had the following duration (figures in parentheses indicate normal ranges in our laboratory): $P-L R A=30 \mathrm{msec}(20-40 \mathrm{msec})$; LRA-H $=60 \mathrm{msec}(50-120 \mathrm{msec}) ; \mathrm{HV}=60 \mathrm{msec}(35-$ $55 \mathrm{msec}$ ). In the presence of complete right bundlebranch block and left anterior hemiblock prolongation of the HV interval indicates that there is an additional 


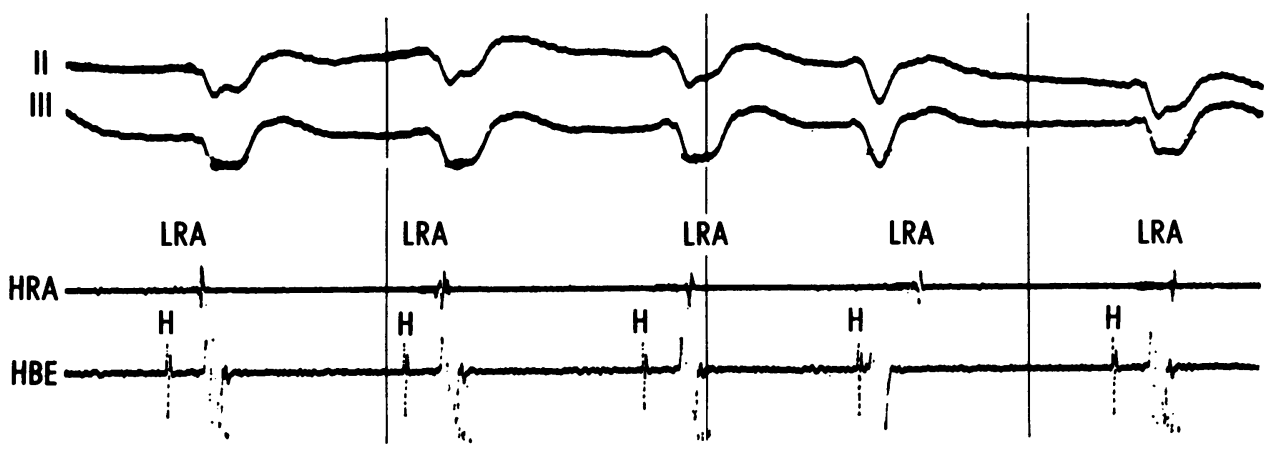

FIG. I (Case I) His bundle rhythm (first, second, third, and fifth beats) with an extrasystole (fourth QRS complex from the beginning of the strip) arising below the bifurcation of the His bundle, in the left bundle-branch or its posteroinferior division. In this and all illustrations paper speed and intervals between vertical lines were $100 \mathrm{~mm} / \mathrm{sec}$ and $1000 \mathrm{msec}$, respectively. $L R A=$ bipolar electrogram from the low right atrium recorded by the His $(H)$ bundle electrographic lead $(H B E) . H R A=$ bipolar electrogram from the high right atrium.

conduction delay in the 'low' His bundle, in the left bundle-branch, or in the posteroinferior division of the left bundle-branch.

This patient had periods of AV dissociation during which a His bundle rhythm coexisted with an independent sinus rhythm (Fig. I). The duration of the HV interval and QRS morphology was more or less the same as that of the sinus beats. In Fig. 1 the fourth $\mathrm{H}$ deflection was premature. It appeared $25 \mathrm{msec}$ after the onset of the premature fourth QRS complex. Since the ventricles were activated before the His bundle, the extrasystole under consideration could not have arisen in the His bundle. Neither did it originate in the free left ventricular wall, for if it had the VH intervals would have been longer (Castellanos et al., 1972). Therefore, impulse formation probably occurred in the left bundle-branch or in its posteroinferior division. The slightly different QRS morphology suggested the presence of asynchronous and abnormal refractoriness in the posteroinferior division, distal to the site of impulse formation.

The surface lead in Fig. 2 showed what appeared to have been type II (Mobitz) AV block, since the third (non-conducted) $P$ wave was preceded by $P R$ intervals of constant duration. On the other hand, the His bundle electrographic lead suggested an alternative explanation: pseudo AV block produced by a concealed premature (third) His bundle deflection. Note that it appeared slightly before the third $\mathbf{P}$ wave. The refractoriness that it created (at either His bundle or AV node) prevented this $\mathbf{P}$ wave from reaching the ventricles.

The premature His bundle depolarization did not activate the ventricles, possibly because (in the presence of a complete right bundle-branch block and left anterior hemiblock) there was an additional area of conduction block in the posteroinferior division of the left bundlebranch distal to the site of impulse formation. The presence of multiple beats arising below the bifurcation of the His bundle (Fig. I) suggested that both manifested and concealed $\mathrm{H}$ deflection had a similar origin. Differences between the morphologies of the corresponding $\mathbf{H}$ deflections do not exclude this diagnosis since it has been suggested by some authors that when using catheter recordings (in contrast to studies with plunge electrodes) the polarity or morphology of the His bundle electrogram might not be very helpful in determining the site (supra- or infra- His bundle) from which the impulse

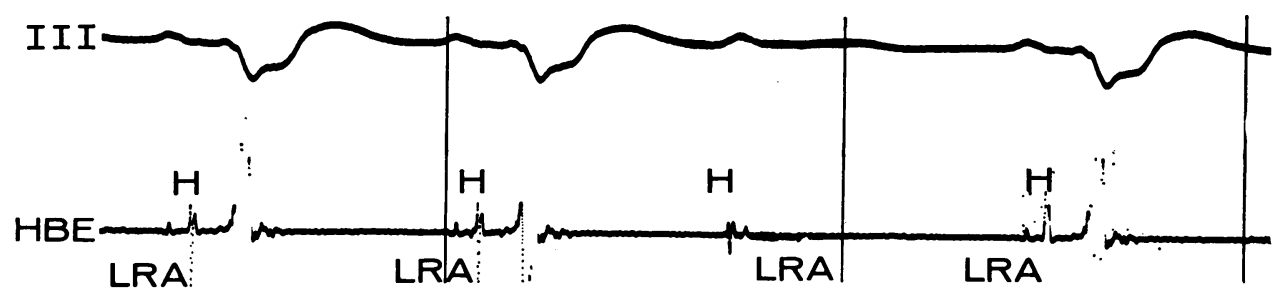

FIG. 2 (Case 2) Pseudo type II (Mobitz) AV block produced by an extrasystole arising below the bifurcation of the His bundle, in the left bundle-branch or its posteroinferior division. 


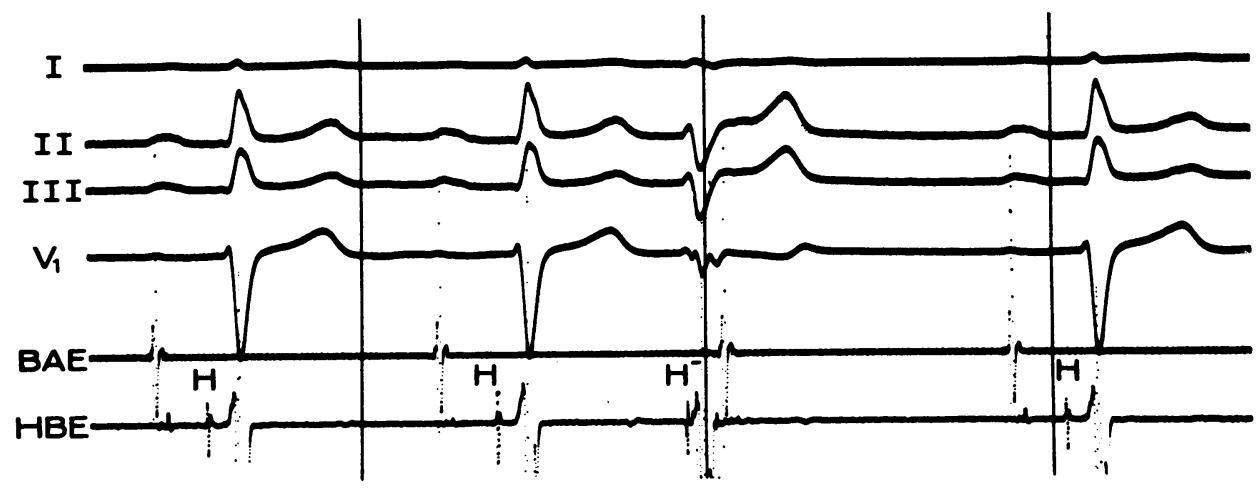

\begin{abstract}
FIG. 3 The third beat is an extrasystole arising in the posteroinferior division of the left bundle-branch. Note the relatively narrow (ectopic) $Q R S$ complex with a left anterior hemiblockincomplete right bundle-branch block pattern. The corresponding $H$ deflection was inscribed 15 msec after the onset of ventricular depolarization, indicating that the His bundle was activated retrogradely from an infra-His bundle site of impulse formation.
\end{abstract}

propagates (Castillo and Castellanos, 1970, I97 I ; Scherlag, Samet, and Helfant, 1972).

To summarize, in this patient pseudo AV block was produced by beats arising below the bifurcation of the His bundle, in the left bundle-branch or its posteroinferior division.

\section{Case 2}

This 62-year-old man was referred for conducting system - studies because of a history of paroxysmal arrhythmias, dizzy spells, and (or) syncopal attacks (Case 3 of the article by Castellanos et al., 1972). The conducted beats (Fig. 3) showed a tendency to right axis deviation (electrical axis of $+80^{\circ}$ ) and narrow ventricular complexes (90 msec).

This patient had extrasystoles which were not preceded by $\mathbf{P}$ waves (third $Q R S$ complex in Fig. 3). In - fact, they did not disturb the basic sinus rhythm. The QRS complexes were slightly prolonged (I IO msec). They showed a superiorly-oriented electrical axis (close to $-90^{\circ}$ ) with an 'incomplete' right bundlebranch block pattern in VI. The His bundle deflection was inscribed $15 \mathrm{msec}$ after the beginning of ventricular depolarization in the surface leads.

This beat did not originate within the His bundle, - because the latter was activated after parts of the ventricles had already been depolarized. Impulse formation in the free ventricular wall was also excluded because of the relatively narrow QRS complex and the short VH interval. As mentioned in the description of Case $I$, if this were the case the ventricular complexes should have been wider and more bizarre. Moreover, a longer VH interval would have been recorded.

- We think, as did Rosenbaum et al. (1970), that the extrasystole arose in the posteroinferior division of the left bundle-branch. From its site of origin the impulse spread towards both the ventricular muscle and His bundle, reaching the latter $15 \mathrm{msec}$ after the former. Initial arrival of excitation at the inferior wall of the left ventricle explains the superiorly-oriented electrical axis. Because right ventricular activation was mainly a function of the wavefront arriving at the right ventricle through the right bundle-branch, the delay in right ventricular activation was of less magnitude than if the impulse had originated in the free wall of the left ventricle (distal to the end of the posteroinferior division) and had to cross the septum to reach the right ventricle. Thus, an 'incomplete', rather than a 'complete', right bundle-branch 'pattern' was produced.

In Fig. 4 the first two beats originated in the sinus node. The conduction intervals had the following values: $P-L R A=30 \mathrm{msec} ; \mathrm{LRA}-\mathrm{H}=190 \mathrm{msec} ; \mathrm{HV}=$ $65 \mathrm{msec} ; \mathrm{PR}=285 \mathrm{msec}$. Thus, both LRA $-\mathrm{H}$ and HV intervals were longer than normal. Prolongation of the $\mathrm{HV}$ intervals in sinus beats with narrow QRS complexes could be due to a conduction delay in: (a) 'low' His bundle, (b) both bundle-branches, or (c) right branch and both divisions of the left bundle-branch.

The third $\mathbf{P}$ wave was non-conducted. The His bundle electrographic lead showed that its blockage was related to the presence of a premature $\mathbf{H}$ deflection with characteristics similar to that seen within the ectopic QRS complex discussed in Fig. 3. However, this premature $\mathbf{H}$ deflection was not associated with a ventricular beat.

If we assume that this patient had an area where conduction was delayed in the right branch and both divisions of the left bundle-branch (which was responsible for the HV prolongation of sinus beats), impulse formation could have occurred at the posteroinferior division (as in Fig. 3) proximally to the affected site. Though the corresponding impulse was unable to reach the ventricles because of the conduction block encountered in the three affected structures, it was still able to activate the His bundle (and perhaps the AV node) retrogradely until colliding with the supraventricular impulse. In 


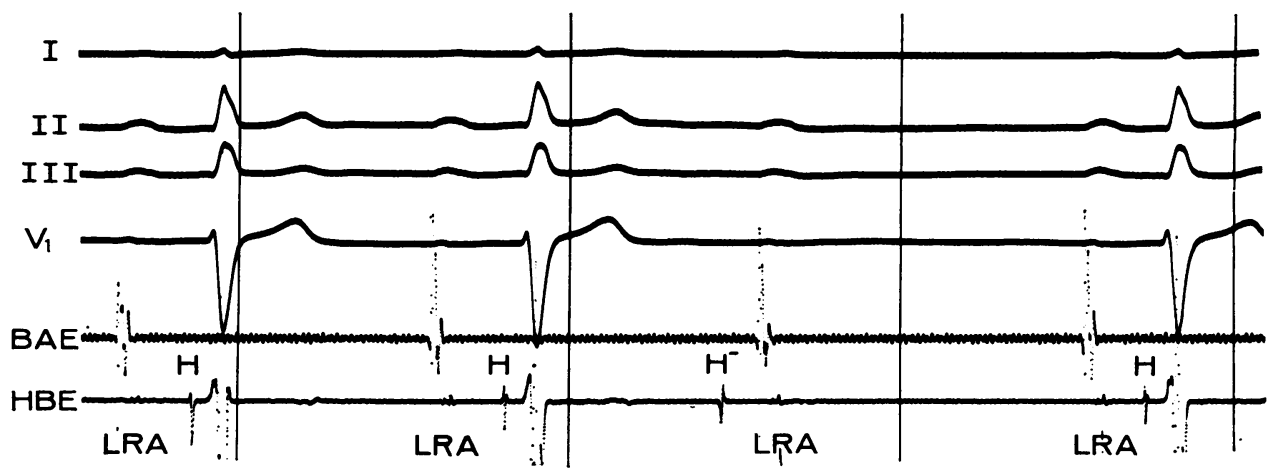

FIG. 4 Pseudo $A V$ block produced by a concealed extrasystole arising in the posteroinferior division of the left bundle-branch. Though unable to activate the ventricles, the ectopic impulse could nevertheless reach the His bundle retrogradely, thereby blocking the oncoming (third) sinus $P$ wave. Note the resemblance between the premature His bundle depolarization and that seen within the ectopic $Q R S$ complex in Fig. 3.

addition to remaining concealed within the AV conducting system, it prevented the third $P$ wave from activating the ventricles.

To summarize, in this patient pseudo AV block was produced by a concealed extrasystole arising below the bifurcation of the His bundle probably in the posteroinferior division of the left bundle-branch.

\section{Comments}

As used in clinical electrocardiography the term 'AV junctional' rhythm implies that impulse formation occurs anywhere between the atrial approaches to the AV node to the so-called bifurcation of the His bundle (Azevedo, Watanabe, and Dreifus, 1972). In fact, His bundle studies have shown that a great number of AV junctional rhythms with preceding activation of the ventricles originate in the His bundle itself (Damato and Lau, 1969). Moreover, intracardiac recordings have proved to be most useful in differentiating between $\mathrm{His}$ bundle rhythms and those arising in the divisions of the left bundle-branch (Castellanos et al., 1972).

In all published cases of pseudo $\mathrm{AV}$ block due to concealed extrasystoles, the latter were believed to have been of AV junctional origin. However, in 1969, Friedberg considered that a similar effect could be produced by ectopic beats arising between the so-called bifurcation of the His bundle and the ventricular myocardium.

The present cases corroborate this assumption as well as the microelectrode studies performed by Myerburg, Stewart, and Hoffman (1970) and Myerburg (197I). These authors observed the forward and retrograde conduction patterns of premature impulses in preparations consisting of a bundlebranch and its multiple terminal ramifications. They observed that action potential duration in the specialized ventricular conduction system increased from bundle-branches distally. The area of maximum action potential duration occurred about $2 \mathrm{~mm}$ proximal to the termination of Purkinje cells in muscle. Because of its specific functional properties, this area was referred to as the peripheral 'gate'. When the bundle-branch was stimulated prematurely at a coupling interval less than the duration of the refractory period of the peripheral 'gate' the premature impulses remained confined (concealed) proximally to the 'gate'.

A similar mechanism could be operating in Fig. 2 and 4. The premature ectopic impulses arising (probably) in the posteroinferior division were unable to reach the ventricles because of the conduction block encountered in the distal part of the ventricular specialized conducting system (right branch and both divisions of the left branch). However, they propagated retrogradely into the His bundle (and perhaps the AV node), therefore preventing the subsequent $\mathbf{P}$ wave from activating the ventricles. Hence, for the purpose of 'concealment' the AV tissues extended from the atrial approaches to the AV node as far down as the peripheral 'gate'.

Yet, we believe that this phenomenon is unusual enough (though not perhaps so much as the low reported incidence suggests) to maintain the classical clinical concept of 'AV junction'. Impulses arising in the latter will produce, in the absence of incomplete recovery of the specialized tissue distal to the bifurcation of the His bundle (aberration) and phase 4 depolarization in infra-Hisian structures, a QRS complex of 'supraventricular' origin, similar to the one produced by sinus $P$ waves. On the other 
hand, those originating below the bifurcation in the ventricular specialized conducting system show relatively narrow $Q R S$ complexes with only slight morphological abnormalities.

\section{Addendum}

Since this manuscript was submitted an article by Cohen, Langendorf, and Pick (1973) has appeared. Analysing Io cases of intermittent parasystole the authors found one case in which the ectopic beats originated in the 'posterior fascicle of the left bundle-branch'. The parasystolic impulses produced a compensatory pause regardless as to whether their discharge was manifested or concealed. In the latter instance they initiated type II (Mobitz) AV block.

\section{References}

Azevedo, I. M., Watanabe, Y., and Dreifus, L. (1972). Reassessment of A-V junctional rhythms. Heart and Lung, 5, 626.

Cannon, D. S., Gallagher, J. J., Goldreyer, B. N., and Damato, A. N. (1972). Concealed bundle of His extrasystoles simulating nonconducted atrial premature beats. American Heart fournal, 83, 777.

Castellanos, A., Jr., O'Brien, H., Castillo, C. A., Myerburg, R. J., and Beffler, B. (1972). Contribution of His bundle recordings to analysis of abnormal beats with right bundlebranch block-superior axis pattern. British Heart fournal, 34, 795 .

Castillo, C., and Castellanos, A., Jr. (197I). Retrograde activation of the His bundle in the human heart. American fournal of Cardiology, 27, 264.

Castillo, C. A., and Castellanos, A., Jr. (1970). Retrograde activation of the His bundle during intermittent paired ventricular stimulation in the human heart. Circulation, 42, 1079.

Cohen, H., Langendorf, R., and Pick, A. (1973). Intermittent parasystole - mechanism of protection. Circulation, 48, 761 .

Damato, A. N., and Lau, S. H. (1969). His bundle rhythm. Circulation, 40, 527.

Eugster, G. S., Godfrey, C. C., Brammell, H. L., and Pryor,
R. (1973). Pseudo A-V block associated with A-H and H-V conduction defects. American Heart fournal, 85, 789.

Friedberg, H. D. (1969). Concealed extrasystoles. American fournal of Cardiology, 24, 283.

Langendorf, R. (1958). Alternation of A-V conduction time. American Heart fournal, 55, $18 \mathrm{I}$.

Langendorf, R., and Mehlman, J. S. (1947). Block (nonconducted) A-V nodal premature systoles imitating first and second degree A-V block. American Heart fournal, 34, 500.

Langendorf, R., and Pick, A. (1966). Concealed conduction in the A-V junction. In Mechanisms and Therapy of Cardiac Arrhythmias, p. 395. Ed. by L. S. Dreifus, W. Likoff, and J. H. Moyer. Grune and Stratton, New York.

Lindsay, A. E., and Schamroth, L. (1973). Atrioventricular junctional parasystole with concealed conduction simulating second degree atrioventricular block. American Fournal of Cardiology, 31, 397.

Myerburg, R.J. (197I). The gating mechanism in the distal atrioventricular conducting system. Circulation, 43, 355.

Myerburg, R. J., Stewart, J. W., and Hoffman, B. F. (1970). Electrophysiological properties of the canine periphereal A-V conducting system. Circulation Research, 26, 36I.

Narula, O. S. (1973). Conduction disorders in the A-V transmission system. In Cardiac Arrhythmias, p. 263 . Ed. by L. S. Dreifus and W. Likoff. Grune and Stratton, New York.

Need, R. L., and Fisch, C. (1962). Heart block resulting from concealed discharge of atrioventricular node. American Fournal of Cardiology, 10, I38.

Rosen, K. M., Rahimtoola, S. H., and Gunnar, R. M. (1970). Pseudo A-V block secondary to premature non-propagated His bundle depolarizations. Documentation by $\mathrm{His}$ bundle electrocardiography. Circulation, 42, 367.

Rosenbaum, M. S., Halpern, M. S., Nau, G. J., Elizari, M. V., and Lazzari, J. O. (1970). The mechanisms of narrow ventricular ectopic beats. In Symposium on Cardiac Arrhythmias, p. 223. Ed. by E. Sandoe, E. FlenstedJensen, and K. H. Oleson. AB Astra, Sodertalje, Sweden. Schamroth, L., and Surawicz, B. (I97I). Concealed interpolated $\mathrm{A}-\mathrm{V}$ junctional extrasystoles and $\mathrm{A}-\mathrm{V}$ junctional parasystole. American fournal of Cardiology, 27, 703.

Scherlag, B. J., Samet, P., and Helfant, R. H. (1972). His bundle electrogram: a critical appraisal of its uses and limitations. Circulation, 46, 60r.

Requests for reprints to Dr. Agustin Castellanos, Heart Station, Jackson Memorial Hospital, Miami, Florida 33152, U.S.A. 